\title{
Exploring the 3D Printing Process for Young Children in Curriculum-Aligned Making in the Classroom
}

\author{
Alexander Berman \\ Texas A\&M University \\ College Station, TX \\ anberman@tamu.edu \\ Elizabeth Deuermeyer \\ Texas A\&M University \\ College Station, TX \\ e.deuermeyer@tamu.edu \\ Beth Nam \\ Texas A\&M University \\ College Station, TX \\ namieu@tamu.edu \\ Sharon Lynn Chu \\ College Station, TX \\ sharilyn@tamu.edu \\ Texas A\&M University \\ College Station, TX \\ quek@tamu.edu
}

Permission to make digital or hard copies of all or part of this work for personal or classroom use is granted without fee provided that copies are not made or distributed for profit or commercial advantage and that copies bear this notice and the full citation on the first page. Copyrights for components of this work owned by others than ACM must be hon ts for componits of this work owned by others than AcM must be honsed. Abstracting with credit is permitted. To copy otherwise, or republish, to post on servers or to redistribute to lists, requires prior specific permis-

IDC '18, June 19-22, 2018, Trondheim, Norway

(C) 2018 Association for Computing Machinery.

ACM ISBN 978-1-4503-5152-2/18/06..\$15.00
https://doi.org/10.1145/3202185.3210799

\begin{abstract}
With increasing focus on integrating 3D printing in educational settings, more emphasis needs to be placed on how to introduce young students to the complexities of the 3D printing process. Inspired by the patrons of 3D printer services, we engage children in a simplified 3D printing process. We conducted a study with two $3^{\text {rd }}$ grade public school science classes over 4 days, where students were tasked to print 3D designs they find online for use in a class presentation. Initial findings identify challenges within this process, and show indications of emerging interest towards 3D printing.
\end{abstract}

\section{Author Keywords}

3D Printing; Children; Elementary school; Thingiverse; Interest; Making; Challenges.

\section{ACM Classification Keywords}

H.5.m. Information interfaces and presentation (e.g., HCI): Miscellaneous.

\section{Introduction}

3D Printing, a means to transform imagination into physical artifacts, has become more common with falling prices and accessible printing software $[1,2]$. 3D printing has also been made more available to children 


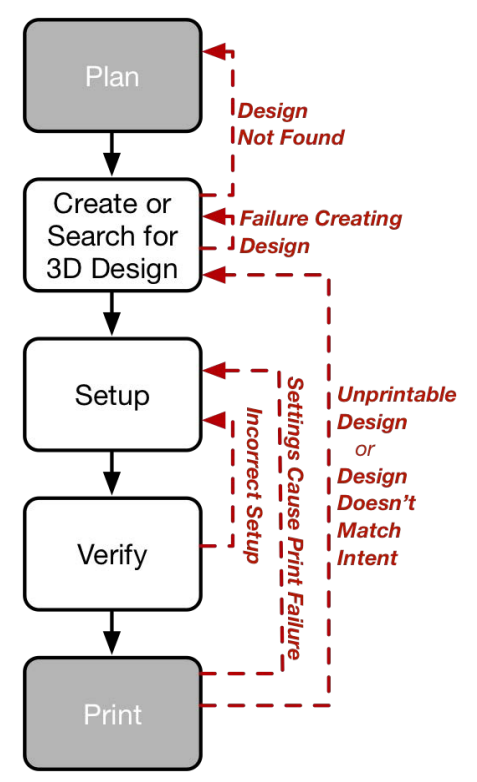

Figure 1: 3D Printing Process for Casual Makers in schools, libraries, and "makerspaces" [3], and pedagogy relating to 3D printing have been investigated [4, 5]. 3D printing offers children a means to satisfy utilitarian needs, promote social good, and provide rapid interventions in their everyday lives [3].

At this time, however, operating 3D printers and 3D modeling are challenging for new users [5-7]. There are many points of failure that can potentially challenge students' sense of self-efficacy and decrease students' interest in 3D printing [6]. Rather than burdening children with learning how to 3D design from scratch in the classroom, they could be initiated to 3D printing by appropriating curricula-relevant designs from online sharing platforms. Hudson et al. explain the 3D printing process for "casual makers", "users who have no prior experience with fabrication and mainly explore walkup-and-use 3D printing services at public print centers" [8]. Casual makers either create or download a 3D model based on a plan, setup and verify that model within printing software, and then print the desired object. Many of these makers download and print designs, rather than always creating designs from scratch. In this paper, we investigate how the 3D printing process of casual makers can be adapted to the classroom to better instill lasting 3D printing interest in students.

\section{Related Work}

Making refers to "an active process of building, designing, and innovating with tools and materials to produce shareable artifacts" [9]. It has been shown to promote values and characteristics such as play, innovation, intrinsic motivation [10] and technological literacy [11]. An important aspect of this Making ethos is the creation of artifacts that are personally significant through technological means, such as 3D printed artifacts. 3D print- ing in educational settings has been shown to empower students and improve their self-esteem [12], also fostering collaboration [13]. Students engaging in 3D printing activities have exhibited benefits such as playfulness and self-expression that are often associated with Making [5, 12]. However, Smith et al. state "students generally lack an understanding of the explorative and sometimes loosely defined processes of digital fabrication in education", suggesting more classroom structure when teaching digital fabrication methods [4].

We present a study on how elementary school-aged students engage in a simplified 3D printing process within a classroom setting and the extent to which the process may prepare them to eventually undertake the full 3D printing process. This simplified casual maker process, adapted from Hudson et al. [8] (Figure 1), removes the steps where a casual maker sets up and verifies 3D printer settings. Rather than being burdened by the complexities of 3D designing and printing software in an introductory activity, students plan what they want to print, search for designs online that meet their planning criteria, and then request a design be printed from a 3D printer operator. Students must revise plans until they find a suitable design to print. Students must search again if a 3D printer operator tells them that the design is infeasible or would not meet their expectations. The simplified 3D printing process for new casual maker students is illustrated in Figure 2.

\section{Study Design and Methodology}

We conducted a study in a third grade classroom with 33 students, ages 8-10. At the time of the study, the students had been engaged in Making-based science learning employing basic electronics kits for over a semester. The study is the first time the students em- 


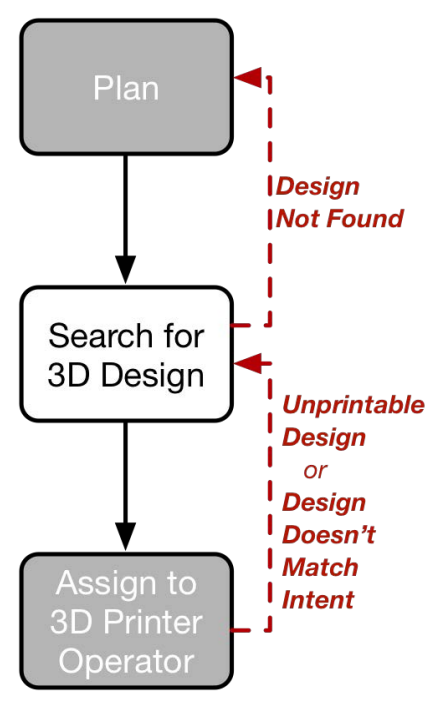

Figure 2: Simplified 3D Printing Process for new Casual Maker Students ployed 3D printing in class over four days, each lasting 45 minutes. The students were from Latino and African populations that are typically underrepresented in STEM-related career fields.

For the study, the topic of the science class was Organisms and Environments. The aim of this lesson was for students to observe and describe physical characteristics of environments and how they support populations within that environment. The students, working in pairs, were randomly assigned one of three environments; park, aquarium, or desert. Students worked towards creating a presentation to describe an assigned environment. They were asked to 3D print an object that could be found in their environment, and incorporate these objects into their presentations. To create their presentation, they could include any of the Making materials they had utilized in past Making activities (e.g. LEDs, vibrating motors, rotating motors, batteries, switches, a push/pull machine, and other arts and craft type materials). Data collected from the study was of four types: observation notes, questionnaire results, transcripts of semi-structures interviews conducted with students, and audio-video recordings.

Day 1. Following a short lecture about organisms and their environments, the students were introduced to the 3D printing process and a website to search and download 3D design to print (Thingiverse.com). They were shown an actual demonstration of printing using the 3D printer in classroom and also talked about some of the constraints in printing, such as size, material, and complexity of printed objects.

Next, groups of students were assigned an environment, and visited Thingiverse to search for relevant keywords. They were given a worksheet that reminded them that they couldn't print anything too large, too complex, or that didn't relate to their presentation. Once they found the model that they wanted, they approached the 3D printing operator, a researcher experienced in 3D printing, to order a print. They discussed with the operator about their decision to print a model and if the model did not meet the printing criteria, they were asked to search for different 3D design files.

Day 2 \& Day 3. Students received the 3D printed objects which were printed by the 3D printing operator on Day 2. On Days 2 and 3, the students worked to complete their presentations. Adult helpers were present to assist the children and did not intervene unless asked by the students. At the end of Day 3, the students presented their projects to the class (e.g. Figure 4).

Day 4. Students completed a questionnaire about their interests, elements of that week's 3D printing activity, and elements of that week's presentation activity as a whole. Some students participated in a semi-structured interview with a member of the research team.

\section{Findings}

A qualitative open coding analysis was performed on the observation notes and interview responses to generate themes of interest with respect to students' interest in 3D printing and challenges faced engaging in the simplified 3D printing process. We utilized Hidi and Renniger's Four-Phase Model of Interest Development [14] as a framework to analyze students' interest in 3D printing, shown in Figure 3. The span of four days of our study does not allow us to infer whether students engaging in the simplified 3D printing process can eventually develop individual interest in 3D printing. 


\section{Four Progressive Levels of Interest}

1 Triggered Situated

- often caused by an external factor (e.g. a specific event an utterance)

\section{Maintained Situational}

Awareness

- focused and persistent

attention to focus issue over a period of time

\begin{tabular}{l}
$3 \quad \begin{array}{c}\text { Emerging Individual } \\
\text { Interest }\end{array}$ \\
- - enduring disposition to focus \\
issue from situational \\
awareness \\
- indicated by: \\
- stored knowledge and value \\
- positive feelings \\
- generate curiosity questions \\
\hline $4 \quad$ Well-Developed \\
\hline - Psychological State-and - Individual Interest \\
Enduring Predisposition to \\
reengage with the focus issue \\
over time
\end{tabular}

Figure 3: Four Levels from Hidi and Renniger's Model of Interest Development

\section{Students' Interest in 3D Printing}

Many of the students had heard of 3D printers, but had not seen one. Situational awareness of 3D printing was Triggered (Figure 3, level 1 ) in the students when the researcher printer-operator compared 3D printers to a hot glue gun. One student exclaimed how she and her mother worked with hot glue guns often, saying it would be fun to also have 3D printers.

Throughout the week of the study, about half of the students moved slowly to maintained situational awareness (Figure 3, level 2). E.g., one pair of students immediately searched '3D Printers' on their browser before environment assignment. They were self-driven and eager to learn more about printers. Another group didn't act as quickly, instead spending more time researching their environment, but one member repeatedly said "we should go to the page (Thingiverse)".

By the end of the four days, there were indications that most of the students in the maintained situational awareness group progressed to emerging individual interest (Figure 3, level 3) in 3D printing. Many students asked curiosity questions about 3D printer operation not mentioned in the first day's introduction. Some students, seeing support material in the printing process, asked about why the print would need that extra plastic. There were many questions about the price of printers and parts. Some students were curious about different constraints of existing printers, such as the range of size and materials of existing 3D-printed artifacts outside the class.

Other indicators of the students' emerging individual interest in 3D printing are their questionnaire and interview responses. In 5-point Likert scale questions, students responded overwhelmingly that they understood and had fun participating in the activity. The results of the questions are shown in Figure 5. When asked what they would print if they had a printer at home, students in the interviews responded with variations of "I would do everything" and "every day I do something". One student said that he wanted to print and build a robot because he "want[s] to be an engineer when [he] grow[s] up".

Challenges in the Simplified 3D Printing Process Students faced several roadblocks in the simplified 3D printing process. Challenges occurred at all three steps of the process. We found three main themes of challenges that the students faced:

\section{Problems in Identifying Object to 3D Print}

Some students had difficulty brainstorming what to print for their environment, reducing the time they had to complete the rest of the 3D printing process. Students that succeeded in planning often relied on past experiences. One group wrote down tigers, because they remember seeing tigers in a desert during a music video. Another wrote down playset equipment for their environment, saying they saw those in "every park".

\section{Spelling and Semantics When Searching} Many students were able to find 3D designs on Thingiverse without much help, but searching online produced some confusion and frustration. One issue was that the $3^{\text {rd }}$ graders had difficulty with spelling, and searches did not offer spelling correction. Hence the queries that would normally yield many results with correct spelling produced no results. Some students would give up on a particular query if a helper did not immediately intervene, and some would find a helper to spell out the desired query. E.g., one group searched 


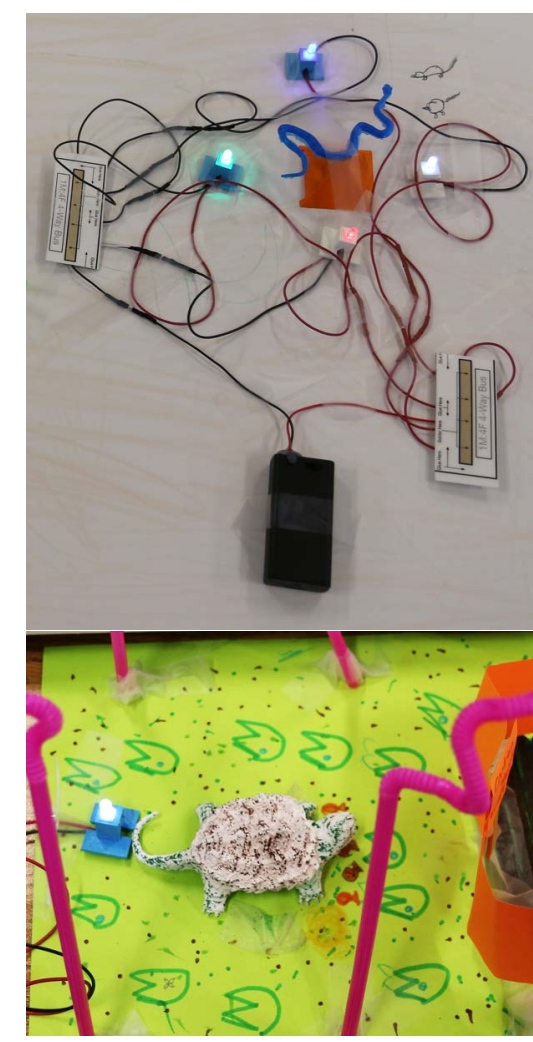

Figure 4: 3D Printed Snake (top) and Snapping Turtle (bottom) in their Respective Environments for whales by searching 'wheels', and needed help to find whale designs. Some query results did not match students intentions. One pair searched for 'slide', and when Thingiverse returned many different slides without playground slides in the top results, they revised their query to 'park slide'. Many students searching animals did not face this issue. E.g., "lion" had fewer semantic meanings than "slide".

\section{Mismatched Expectations}

Students often chose 3D designs based on certain key attributes, e.g., degree of shininess, color, etc. Thus, when initially ordering their designs, students would often imagine the printed artifacts based on their presentation on Thingiverse. E.g., a pair of students searching for rabbits for their park chose a model because of complex coloring in the preview image. Students were previously instructed that prints would be a random solid color, but many still expected colors shown online. Another pair chose a fish model to be printed since it appeared large online. The operator clarified that the fish could be made smaller by rescaling. To help attenuate students' disappointments, the operator always asked questions about why the students chose a particular design, and communicated any differences between students' expectations, curricula expectations, and 3D printer capabilities with respect to the students' desired print.

\section{Focus on Visuals than Semantics}

Students were more interested in printing designs for their visual qualities rather than semantic relevance for their presentations. This highlights that given its strong visual attraction, 3D printing in educational usage faces the challenge of relevance for it to be a tool to support learning. E.g., some students selected designs because "we thought it was cute. We liked it" and "it looked like
Mufasa... from the Lion King". When asked how it related to their assigned environment, many students simply said it belonged in the environment, but did not explain how they would incorporate it in a presentation.

\section{Discussion and Future Work}

Through the simplified casual maker 3D printing process, some students appeared to have gained an emergent interest in 3D printing. Growing self-efficacy was also apparent in students' claims that they liked and were good at 3D printing. However, further study will be needed to see if any emergent interest persists to become a well-developed interest after this one class. Future work will track these students' future interactions and interests in 3D printing in the classroom.

One challenge in our classroom-based study is that students incorporated the 3D objects into the environment after thinking about what to print. This means that while they thought about how the 3D artifact they chose to print must belong to the environment, they did not plan how to present with their printed artifact. This may be a reason why many prints were displayed in a mainly stand-alone, decorative manner in the presentations. This result may indicate a triggered situated awareness, but does not guarantee any progression of interest. This could instead lead students to develop Blikstein's "Keychain Syndrome" [12], where students recreate items with a similar process and not explore new concepts. This concern is reinforced by the many students' expressed wishes to print out more animals and park equipment in the interviews. While these may be signs of maintained situational awareness, they implicitly also show that those students did not consider what they could print outside of their presentation activity. It is possible that students' inter- 


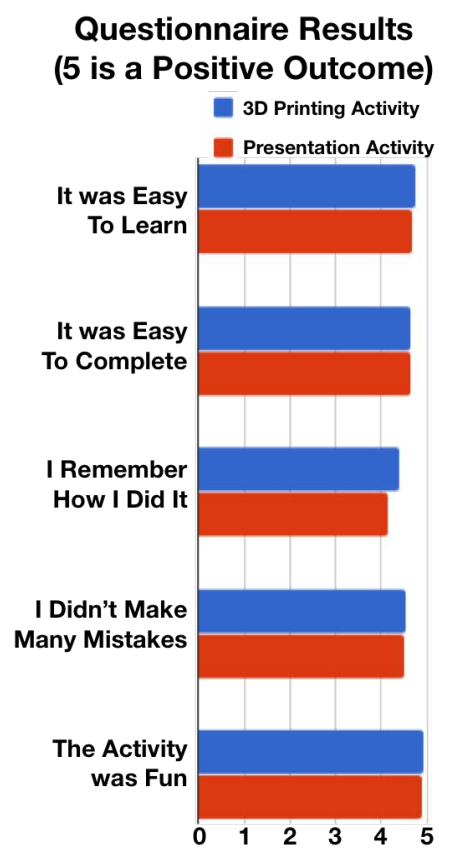

Figure 5: Likert-Scale

Questionnaire Results from Day 4 on 3D Printing

Experiences and on the Presentation Activity as a whole ests may progress to such out-of-task curiosity questions, but may need further support to do so.

Students often faced the challenge of mismatched expectations between the digital representations of the $3 \mathrm{D}$ designs online and the likely result of printing those objects in the classroom. This is similar to results of Baudisch and Mueller, where they note that 3D printing is presently lacking "what-you-see-is-what-you-get" interfaces to help people make more sense of 3D printing digital media [15]. Future work could investigate how to help children better-evaluate online 3D designs.

\section{Conclusion}

We presented initial findings from an investigation into how introducing 3D printing through a simplified process can initiate young students to 3D printing as a technology for Making. Our first observations suggest that many students in the class developed an emerging interest towards 3D printing, but students had a range of difficulties, including searching and evaluating 3D designs online for printing. Future work will generate guidelines as to how the simplified 3D printing process can be supported for young children, e.g., with features like spelling correction in the search process.

\section{References}

[1] Barrett, B. ThingMaker is for kids, But You'll Want This 3-D Printer for Yourself. Wired Magazine, 18 (2016).

[2] Eisenberg, M. 3D printing for children: What to build next? International Journal of Child-Computer Interaction, 1, 1 (2013), 7-13.

[3] McNally, B., Norooz, L., Shorter, A. and Golub, E. Toward Understanding Children's Perspectives on Using 3D Printing Technologies in their Everyday Lives. ACM, 2017.
[4] Smith, R. C., Iversen, O. S. and Hjorth, M. Design thinking for digital fabrication in education.

International Journal of Child-Computer Interaction, 5 (2015), 20-28.

[5] Stickel, O., Hornung, D., Aal, K., Rohde, M. and Wulf, V. 3D Printing with marginalized children-an exploration in a Palestinian refugee camp. Springer, 2015.

[6] Maltese, A. V., Simpson, A. and Anderson, A. Failing to learn: The impact of failures during making activities. Thinking Skills and Creativity (2018).

[7] Posch, I. and Fitzpatrick, G. First steps in the FabLab: experiences engaging children. ACM, 2012.

[8] Hudson, N., Alcock, C. and Chilana, P. K. Understanding newcomers to $3 D$ printing: motivations, workflows, and barriers of casual makers. ACM, 2016.

[9] Litts, B. K. Making learning: Makerspaces as learning environments. The University of WisconsinMadison, 2015.

[10] Honey, M. and Kanter, D. E. Design, make, play: Growing the next generation of STEM innovators. Routledge, 2013.

[11] Angello, G., Chu, S. L., Okundaye, O., Zarei, N. and Quek, F. Making as the New Colored Pencil: Translating Elementary Curricula into Maker Activities. ACM, 2016.

[12] Blikstein, P. Digital fabrication and 'making'in education: The democratization of invention. FabLabs: Of machines, makers and inventors, 4 (2013), 1-21.

[13] Schelly, C., Anzalone, G., Wijnen, B. and Pearce, J. M. Open-source 3-D printing technologies for education: Bringing additive manufacturing to the classroom. Journal of Visual Languages \& Computing, 28 (2015), 226-237.

[14] Hidi, S. and Renninger, K. A. The four-phase model of interest development. Educational psychologist, 41, 2 (2006), 111-127.

[15] Baudisch, P. and Mueller, S. Personal fabrication. Foundations and Trends $₫$ in Human-Computer Interaction, 10, 3-4 (2017), 165-293. 